ВІСНИК

ОДЕСЬКОГО НАЦІОНАЛЬНОГО

МОРСЬКОГО УНІВЕРСИТЕТУ

№ 2 (59), 2019
HERALD

OF THE ODESSA NATIONAL

MARITIME UNIVERSITY

№ 2 (59), 2019

УДК 536.24(075.8)

DOI 10.33082/2226-1915 -2-2019-121-126

\title{
ВЫБОР ОПТИМАЛЬНОГО ДАВЛЕНИЯ ПРОМЕЖУТОЧНОГО ПЕРЕГРЕВА ПАРА В ЦИКЛЕ ПАРОТУРБИННОЙ УСТАНОВКИ
}

\author{
А.А. Вассерман \\ доктор технических наук, профессор кафедры \\ «Судовые энергетические установки и техническая эксплуатация» \\ Одесский национальный морской университет
}

\begin{abstract}
Аннотация. Предлагается методика выбора оптимального давления промежуточного перегрева пара в цикле паротурбинной установки (ПТУ). Для этого рассчитываются значения термического КПД иикла ПТУ при нескольких значениях давления промежуточного перегрева. Приведены результаты расчётов термического КПД при начальном давлении пара 6, 8 и 10 МПа и давлении конденсащии 0,005 МПа. Анализ этих результатов показал, что оптимальными значениями давления промежуточного перегрева являются соответственно 1,2, 1,5 и 2,4 МПа.

Ключевые слова: паротурбинная установка, промежуточный перегрев пара, температура и давление пара, иикл Ренкина, термический КПД иикла, степень сухости пара.
\end{abstract}

УДК 536.24(075.8)

DOI 10.33082/2226-1915 -2-2019-121-126

\section{ВИБІР ОПТИМАЛЬНОГО ТИСКУ ПРОМІЖНОГО ПЕРЕГРІВУ ПАРИ В ЦИКЛІ ПАРОТУРБІННОЇ УСТАНОВКИ}

\author{
О.А. Вассерман \\ доктор технічних наук, професор кафедри \\ «Суднові енергетичні установки та технічна експлуатація» \\ Одеський національний морський університет
}

Анотація. Пропонується методика вибору оптимального тиску проміжного перегріву пари в ииклі паротурбінної установки (ПТУ). Для иього розраховуються значення термічного ККД ииклу ПТУ при декількох значеннях тиску проміжного перегріву. Наведені результати розрахунків термічного ККД при початковому тиску пари 6, 8 и10 МПа і тиску конденсащії 0,005 МПа. Аналіз циих результатів показав, щзо оптимальними значеннями тиску проміжного перегріву є відповідно 1,2, 1,5 и 2,4 МПа.

(C) Вассерман А.A., 2019 
Ключові слова: паротурбінна установка, проміжний перегрів пари, температура и тиск пари, цчикл Ренкіна, термічний ККД циклу, степінь сухості пари.

UDC 536.24(075.8)

DOI 10.33082/2226-1915 -2-2019-121-126

\title{
CHOOSE OF OPTIMAL PRESSURE OF INTERMEDIATE OVERHEATING OF VAPOR AT STEAM-TURBINE PLANT CYCLE
}

\author{
A.A. Vasserman \\ Doctor of technical sciences, Profesor of department \\ «Ships energetic plants and technical operation» \\ Odessa National Maritime University
}

\begin{abstract}
The method of choose of optimal pressure of intermediate overheating of vapor at steam-turbine plants (STP) cycle is proposed. For this aim values of thermal coefficient of efficiency of STP cycle at several values of intermediate overheating pressure are calculated. The results of calculations of thermal coefficient of efficiency at initial pressures 6, 8 and $10 \mathrm{MPa}$ and condensation pressure 0,005 MPa are presented. The analysis of these results showed, that optimal values of intermediate overheating pressure are 1,2, 1,5 and 2,4 MPa correspondingly.

Keywords: steam-turbine plant, intermediate overheating of vapor, temperature and pressure of vapor, Rankine cycle, thermal coefficient of efficiency, degree of vapor dryness.
\end{abstract}

Введение. В современные паротурбинных установках для обеспечения приемлемого значения степени сухости пара в конце его расширения в турбине применяется промежуточный перегрев пара [1-4]. При удачном выборе параметров промежуточного перегрева можно обеспечить некоторое повышение термического КПД цикла ПТУ. Температура пара в конце промежуточного перегрева обычно несколько ниже его температуры после основного пароперегревателя (на $\left.10-20^{\circ} \mathrm{C}\right)$. В настоящей работе предлагается методика выбора оптимального давления промежуточного перегрева.

Целью статьи является определение при заданных значениях начального давления пара и давления конденсации оптимального давления промежуточного перегрева пара, обеспечивающего наибольшее возможное повышение термического КПД цикла ПТУ.

Изложение основного материала. На рис. 1 представлены в координатах T,s цикл ПТУ с промежуточным перегревом пара и цикл Ренкина. Из рисунка 1, а видно, что при давлении промперегрева, близком к максимальному давлению цикла, температура пара в процессе 
ВІСНИК

ОДЕСЬКОГО НАЦІОНАЛЬНОГО МОРСЬКОГО УНІВЕРСИТЕТУ № 2 (59), 2019
HERALD

OF THE ODESSA NATIONAL

MARITIME UNIVERSITY № 2 (59), 2019

промперегрева будет выше средней температуры подвола теплоты в процессе 3-4-5-6. Однако количество подведенной теплоты будет небольшим, поэтому термический КПД цикла с промперегревом по сравнению с КПД цикла Ренкина возрастёт незначительно.
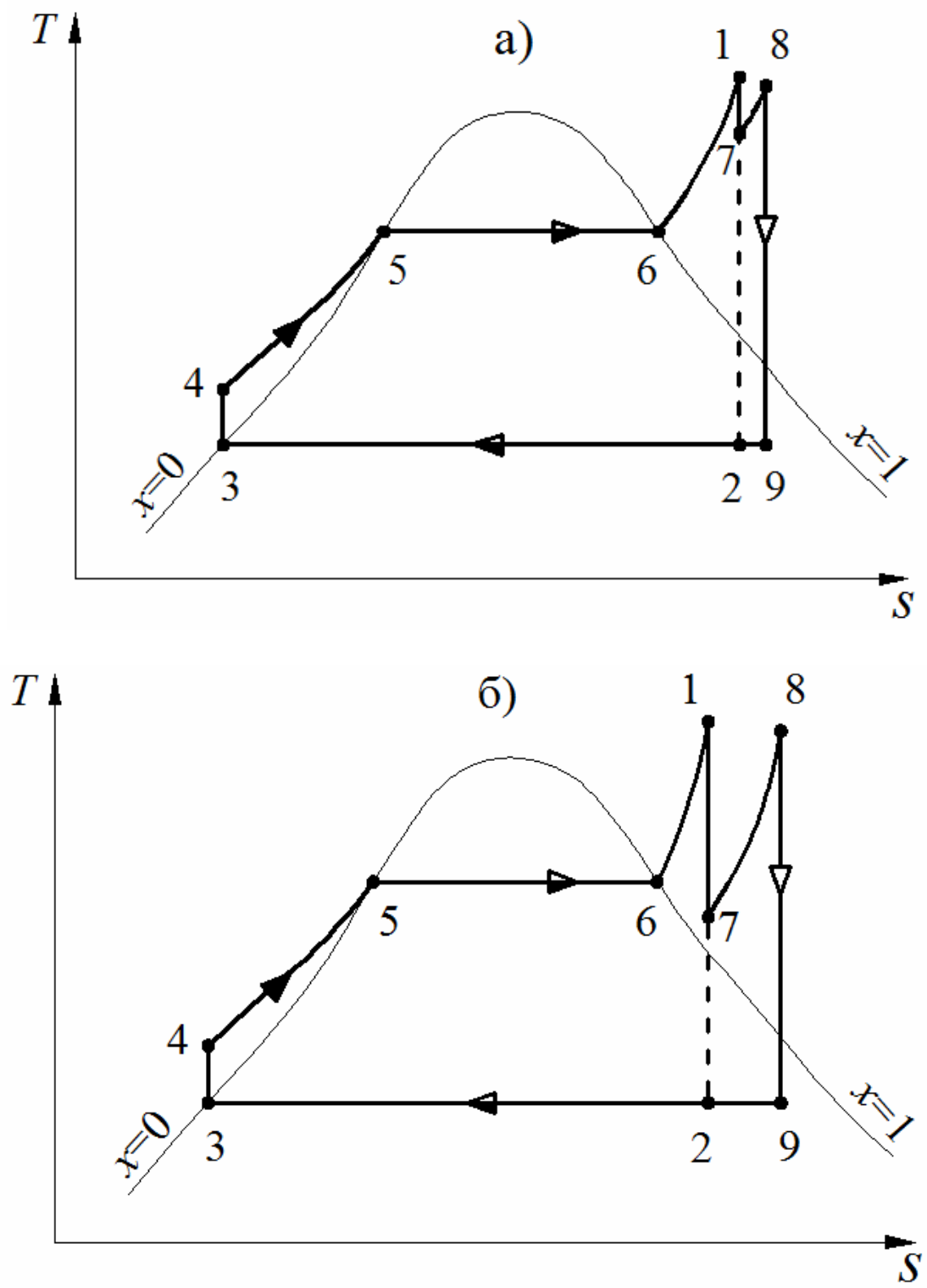

Рис. 1. Цикл ПТУ с промежуточным перегревом пара 1-7-8-9-3-4-5-6-1 и ичикл Ренкина 1-2-3-4-5-6-1 
При дальнейшем уменьшении давления промперегрева (рис.1, б) средняя температура процесса 8-9 несколько снизится, но останется выше средней температура процесса 3-4-5-6.

В то же время заметно увеличится количество теплоты, подводимой в процессе 8-9, поэтому термический КПД цикла с промперегревом будет возрастать. Наконец, при существенном снижении давления промперегрева термический КПД начнёт уменьшаться вследствие снижения средней температуры подвода теплоты при промперегреве.

Таким образом, зависимость термического КПД цикла ПТУ от давлении проперегрева должна иметь максимум. Этому максимуму соответствует оптимадьное значение давления промперегрева.

Для исследования взаимосвязи между значениями параметров пара при промперегреве и термическим КПД цикла были приняты значения начального давления 6,8 и $10 \mathrm{MПа,} \mathrm{давления} \mathrm{конденсации} 0,005$ МПа,, начальной температуры пара $500 \mathrm{C}$ и температуры промперегрева 490 С. При расчётах использованы данные о термодинамических воды и водяного пара из таблиц М.П. Вукаловича и соавторов [5]. Расчёты проводились при различных значениях давления промперегрева. Часть результатов расчётов, соответствующая максимальным значениям термического КПД, представлена в таблице.

Таблица

\section{.Давления промежуточного перегрева}

в районе максимальных значений термического КПД

\begin{tabular}{|c|c|c|c|c|c|}
\hline \multicolumn{6}{|c|}{ Начальное давление пара и КПД цикла Ренкина } \\
\hline 6 МПа & 0,4022 & $8 \mathrm{MПа}$ & 0.4121 & \multicolumn{1}{|c|}{10 МПа } & 0,4194 \\
\hline$p_{\text {пп, МПа }}$ & КПД & $p_{\text {пп }}$, МПа & КПД & $p_{\text {пп, МПа }}$ & КПД \\
\hline 1,5 & 0,4177 & 2,5 & 0,4262 & 2,8 & 0,4334 \\
\hline 1,3 & 0,4179 & 2,0 & 0,4268 & 2,5 & 0,4336 \\
\hline $\mathbf{1 , 2}$ & $\mathbf{0 , 4 1 8 0}$ & $\mathbf{1 , 5}$ & $\mathbf{0 , 4 2 6 9}$ & $\mathbf{2 , 4}$ & $\mathbf{0 , 4 3 3 6}$ \\
\hline 1,0 & 0,4179 & 1,2 & 0,4264 & 2,3 & 0,4336 \\
\hline 0,8 & 0,4173 & 1,0 & 0,4257 & 2,0 & 0,4335 \\
\hline
\end{tabular}

Анализируя данные таблицы, можно установить следующее:

- чётко определяется оптимальное значение давления промперегрева, которому соответствует максимум термического КПД цикла;

- более высокому начальному давлению пара соответствует более высокое значение оптимального давления промперегрева;

- максимальное значение термического КПД цикла с промперегревом при принятых нами в расчётах параметрах пара больше терми- 
ческого КПД цикла Ренкина при начальном давлении пара 6,8 и 10 МПа на $0,0058,0,0148$ и $0.0142(1,44,3,59$ и $3,39 \%)$ соответственно;

- при указанных выше значениях начальных параметров пара термический КПД цикла увеличивается при повышении начального давления пара.

Выводы. Расчёт цикла ПТУ с промперегревом позволил определить взаимосвязь между значениями параметров пара при промперегреве и термическим КПД цикла. Выполнена количественная оценка максимального увеличения термического КПД цикла с промперегревом по сравнению с КПД цикла Ренкина.

Предложено выбирать в качестве оптимального значения давления промперегрева то значение, которому соответствует максимум термического КПД цикла. Эти соображения следует учитывать при проектировании паротурбинных установок.

\section{СПИСОК ЛИТЕРАТУРЫ}

1. Техническая термодинамика / В.А. Кириллин, В.В. Сычев, А.Е. Шейндлин. М.: Издательский дом МЭИ, 2008. 496 c.

2. Техническая термодинамика / М.П. Вукалович, И.И. Новиков. М.: Энергия, 1968. 496 с.

3. Лекиии по технической термодинамике / Я.3. Казавчинский. M.: Транспорт, 1970. 275 c.

4. Термодинамічні процеси та цикли в реальному газі / О.А. Вассерман, О.Г. Слинько. Одеса: Фенікс, 2015. 194 с.

5. Таблищы теплофизических свойств воды и водяного пара / М.П. Вукалович, С.Л. Ривкин, А.А. Александров. М.: Изд-во Стандартов. 1969. 408 c.

\section{REFERENCES}

1. Kirillin V.A., Sychev V.V., Sheydlin A.E.(2008) Texnicheskaya termodinamika [Technical thermodynamics] Moscov: Izdatelskii dom MEI.(in Russian).

2. Vukalovich M.P., Novikov I.I. (1968) Texnicheskaya termodinamika [Technical thermodynamics] Moscov: E'nerhiya. (in Russian).

3. Kazavchinskiy Ya.Z. (1970) Lektsii po texnicheskoi termodinamike [Lectures on technical thermodynamics]. Moscov:Transport. (in Russian). 
4. Vasserman O.A.,Slyn'ko O.G.(2015) Termodinamichni protsessy ta tsykly $v$ real'nomu gazi [Technological processes and cycles in real gas]Odesa:Feniks. (in Ukrainian)

5. Vukalovich M.P., Rivkin S.L., Aleksandrov A.A. (1969) Tablitsy' teplofizicheskix svoystv vody' $i$ vodyanogo para [Tables of technological properties of water and water vapor] Moscov: Izdatelstvo Standartov. (in Russian)

Стаття надійшла до редакиії 12.12 .2019

\section{Рещензенти:}

доктор технічних наук, завідувач кафедри «Суднові енергетичні установки та технічна експлуатація» Одеського національного морського університету Р.А. Варбанець

кандидат технічних наук, завідувач кафедри «Суднова теплоенергетика» Національного університету «Одеська морська академія» O.B. Kipic 